\title{
A Dominialidade Privada dos Recursos Hídricos em face do Desenvolvimento Sustentável
}

\section{The Dominion Private Water Resources in THE Face of Sustainable DeVelopment}

\author{
Nicanor Henrique Armando * \\ Maristela Aparecida Oliveira Valadão **
}

Resumo: O presente artigo apresenta uma breve reflexão acerca da trajetória do domínio dos recursos hídricos no Brasil. A evolução da tutela jurídica dos recursos hídricos demonstra que, na vigência do Código de Águas, a proteção jurídica das águas limitava-se a conflitos de vizinhança e geração de energia, sem preocupação com sua preservação. Todavia, o acelerado processo de industrialização passou a exigir um maior aporte de recursos hídricos e, para promover o uso racional e garantir os múltiplos usos, era necessária uma proteção jurídica mais eficaz e condizente com o novo panorama, papel absorvido pela Constituição da República de 1988. Posteriormente, a Lei das Águas, em 1997, que instituiu a Politica Nacional de Recursos Hídricos, implementou os ditames constitucionais, destacando a água como um bem público, dotado de valor econômico, cujo planejamento e gestão do uso devem ocorrer de forma sustentável. Ao se atribuir um valor econômico à água, indaga-se se o uso racional vem sendo realmente alcançado ou, se através de um discurso da escassez, estaria sendo privatizado, ou mesmo, se os instrumentos da outorga e cobrança de uso asseguram o uso sustentável dos recursos hídricos. Salienta-se que a água é um direito fundamental de todos e é nesse sentido que seu domínio deve ser orientado. Entretanto, existe um caminho tortuoso a trilhar para banir a dominialidade privada dos recursos hídricos e promover o consumo ético da água, essencial para a implementação de uma gestão hídrica sustentável.

Palavras-chave: Recursos hídricos. Domínio privado. Direito fundamental. Sustentabilidade.

Abstract: This article presents a brief reflection on the history of the field of water resources in Brazil. The evolution of the legal protection of water resources shows that the effect of the Water Code, the legal protection of waters was limited to neighborhood disputes and power generation, without concern for its preservation. However, the rapid industrialization 
process has required a greater intake of water resources and to promote the rational use and ensure multiple uses, it required a more effective legal protection and consistent with the new panorama, paper absorbed by the Constitution of the Republic of 1988. Subsequently, the Water Law in 1997, which established the National Water Resources Policy, implemented the constitutional principles, highlighting water as a public good with economic value, whose use planning and management must occur in a sustainable manner. When you assign an economic value to water, asks if the rational has been actually achieved, or through a discourse of scarcity, was being privatized, or even if the instruments of grant and collection of use ensure the sustainable use water resources. It is noted that water is a fundamental right of all and that is what your domain should be oriented. However, there is a tortuous path to tread to ban the private dominion of water resources and promote ethical consumption of water, essential for the implementation of a sustainable water management.

Keywords: Water resources. Private domain. Fundamental right. Sustainability. 


\section{INTRODUÇÃO}

O ser humano sempre vislumbrou a água como algo inesgotável, o que dificulta a imposição de limites ao uso desse bem ambiental tão precioso. Entretanto, a cultura do desperdício ainda se faz presente e os sintomas da escassez vêm sendo percebidos. O quadro tende a se agravar com a demanda de maior aporte de água potável advinda do crescimento populacional, da produção industrial, da agricultura irrigada, da contaminação, da gestão pública deficitária do patrimônio hídrico, dentre outros fatores.

O Brasil é uma nação privilegiada, pois conta com recursos hídricos em abundância. Todavia, a distribuição não é uniforme, vez que parte significativa da população ainda não tem acesso à água: enquanto regiões áridas e semiáridas são carentes em recursos hídricos, outras, como a região sudeste, são beneficiadas, mas a água disponível é de má qualidade. Percebe-se, portanto, que a escassez não é somente quantitativa, mas também qualitativa, o que exige posturas rígidas e diferenciadas de gestão hídrica.

Os recursos hídricos apresentam diversas funções que, certamente, lhes conferem múltiplos usos, os quais devem ser assegurados por meio de um arcabouço jurídico protetivo bem delineado, o qual só se concretiza mediante a implementação de uma efetiva gestão dos recursos hídricos e com o uso ético.

A Constituição Federal de 1988 rompeu com o paradigma do domínio particular das águas e instituiu o domínio público, o que motivou a necessidade de se estabelecer um regime jurídico de águas, o qual, na atualidade, é implementado pela Lei de Política Nacional de Recursos Hídricos (LNPRH).

Tendo em vista a imprescindibilidade da água à sobrevivência humana, esta passou a gozar de especial proteção e seu acesso alcançou o status de direito humano fundamental. Sendo assim, além ser alçada a um bem de todos, de titularidade difusa, deve ser garantido o seu uso prioritário, em situações de escassez, para o consumo humano e dessedentação de animais.

Salienta-se que, embora o país seja imerso em água, a abundância hídrica não se perpetua sem medidas de controle do uso da água para garantir o acesso às gerações presentes e futuras. Assim, se faz necessário atribuir um valor econômico à água para que se promova, por meio da cobrança, o seu uso racional e a internalização dos custos do uso hídrico.

Destaca-se que agregar um valor econômico aos recursos hídricos não significa mercantilizar a água, mas sim utilizar-se da economia ambiental para evitar o desperdício, promover o reúso e preservar os múltiplos usos, enfim, 
garantir a gestão sustentável do bem comum, imprescindível à sadia qualidade de vida e, sobretudo, impedir a privatização dos recursos hídricos.

Diante de tais premissas, surgem os seguintes questionamentos: qual o regime jurídico de propriedade das águas no contexto do desenvolvimento sustentável, delineado pela ordem constitucional? A atribuição de um valor econômico à água realmente promove o uso racional e soluciona o problema da escassez, ou promove, via reflexa, um retorno à apropriação privada? Os principais instrumentos existentes no arcabouço jurídico, como a outorga e cobrança de uso dos recursos hídricos, asseguram o cumprimento da função social da propriedade? A fixação de um preço para o consumo privado, inspirada no princípio do usuáriopagador, ao invés de evitar o uso indiscriminado de tal recurso, não estaria estimulando o consumo irracional?

Conforme será destacado, a LNPRH acompanhou a diretriz constitucional ao publicizar o domínio das águas que, mesmo presentes em propriedades privadas, são bens de uso comum do povo e essenciais à manutenção da vida, não cabendo, portanto, a apropriação privada, o que só se permite mediante a outorga do direito de uso pelo órgão competente.

Salienta-se ainda que não basta garantir o direito fundamental de todos ao acesso à água, voltada para o mínimo existencial; deve-se observar o uso sustentável dos recursos hídricos e é nesse sentido que se estabelece o objetivo do presente estudo: verificar se o uso das águas "particulares" compatibiliza-se com o princípio do desenvolvimento sustentável.

Para a abordagem do tema, pretende-se, através do método dedutivo, traçar contornos sobre a importância da água, funções e usos múltiplos e discorrer, de forma sucinta, sobre a evolução histórica do direito hídrico no Brasil, destacando a dominialidade pública da água e alguns pontos mais importantes da Política Nacional de Recursos Hídricos. Partindo de fundamentos da doutrina e precedentes jurisprudenciais, ingressa-se na discussão em torno do manejo sustentável dos recursos hídricos, considerando-se o aspecto dúplice das águas como bem de titularidade difusa e como recurso econômico.

Sem a pretensão de esgotar o assunto, trata-se de um tema de extrema relevância, face à crise mundial de escassez dos recursos hídricos, que tende a se agravar nas próximas décadas, se não observadas e implementadas as legislações que tutelam os recursos hídricos. Concretizar o direito fundamental à água como um bem comum de todos e não de poucos constitui uma tarefa árdua que só poderá ser cumprida mediante um consumo ético, com a preservação da qualidade e utilização sustentável dos mananciais. 


\section{GENERALIDADES SOBRE AS ÁGUAS}

Apesar de ser um bem ambiental abundante no planeta, a água encontrase ameaçada pelo modelo consumista que perpetua na sociedade pós-moderna, o que desafia a garantia de acesso a ela, quantitativo e qualitativo, para a sobrevivência humana.

Segundo a Organização das nações Unidas, mais de um bilhão de pessoas não têm acesso à água, o que representa 20 por cento da população mundial, um patamar que pode aumentar se não houver uma redução significativa nas taxas crescimento populacional, acompanhada da implementação de medidas políticas para amenizar a crise. O problema tende a se agravar em países em desenvolvimento como o Brasil, que vem experimentando um crescimento econômico, pautado na expansão da agricultura para exportação de commodities e aumento da produção industrial.

A crise de água não decorre apenas de fatores climáticos e geográficos, pois o ciclo hídrico permanece o mesmo durante bilhões de anos, resulta principalmente da ação antrópica e da externalização dos custos referentes aos usos dos recursos hídricos.

Ainda que o país seja imerso em água, é necessário adotar uma postura mais conservacionista porque, como bem adverte Elói Ampessan Filho (2010, p.201), "não temos por hábito dar a devida atenção a estes problemas, ao contrário, ignoramos, pois cremos que nunca baterão à nossa porta, ou terão qualquer influência em nossos hábitos, nossas vidas, o que é um equívoco, uma vez que os problemas estão plantados, são reais".

Dificilmente emerge, portanto, a necessidade de buscar soluções para a crise que envolve os recursos hídricos, que devem partir, principalmente, da implementação de uma adequada política de gestão dos recursos hídricos que melhore o aproveitamento da água disponível e permita que as atividades econômicas como agricultura, indústria, comércio, geração de energia, turismo, navegação e outras, se desenvolvam sem comprometer os estoques das gerações futuras.

\subsection{Conceito, funções e classificação}

O conceito da água vai muito além do conceito físico-químico que se tem em mente: substância líquida, incolor, inodora, formada por duas moléculas de hidrogênio e uma de oxigênio. O real conceito agrega valores sociais, culturais, 
políticos, científicos, econômicos, geográficos, religiosos que não podem ser desconsiderados para o estabelecimento de uma gestão hídrica legítima.

Independente de qualquer definição, a água é um bem comum, essencial à manutenção da vida no planeta e se traduz, por sua natureza jurídica, em um bem ambiental fundamental à garantia da dignidade da pessoa humana. Enquadra-se como um bem comum, não se sujeitando à apropriação pelo particular.

Ainda que se disponha de várias classificações, o presente estudo limitase às águas superficiais e subterrâneas. As primeiras são aquelas que escoam ou se cumulam na superfície do solo como lagos, rios, riachos e as subterrâneas são aquelas que se infiltram no solo e alcançam camadas profundas do subsolo, formando uma espécie de reservatório natural - os denominados aquíferos.

O Brasil é muito rico em lençóis freáticos e as águas subterrâneas constituem importante fonte de abastecimento, pois detêm água de boa qualidade, facilmente exploradas a um custo baixo. Contudo, a perfuração de poços artesianos progride sem regulamentação eficaz e fiscalização dos órgãos gestores, o que pode ocasionar a poluição dos lençóis subterrâneos e também gerar instabilidades no solo.

\subsection{Os múltiplos usos das águas}

A água sempre serviu à humanidade para diversos usos como consumo humano, geração de energia, irrigação na agricultura, industrial, navegação, recepção de resíduos, pesca, lazer, abastecimento industrial, científico, medicinal, dentre outros. A agricultura apresenta-se como maior usuário, variando em torno de $75 \%$, acompanhada pela indústria com $20 \%$ e uso doméstico com $5 \%$. (D`ISEP, 2010, p.29).

Os múltiplos usos geram diferentes efeitos: enquanto usos como abastecimento urbano e irrigação implicam perda quantitativa, outros deterioram a qualidade das águas, como ocorre com a contaminação química e orgânica dos rios. Outros como a produção de energia hidrelétrica, por sua vez, não acarretam praticamente prejuízo quantitativo nem qualitativo, mas atingem aspectos ecológicos que indiretamente afetam a disponibilidade dos recursos hídricos.

Independente dos usos, a preservação dos recursos hídricos é de fundamental importância para assegurá-los. Desta feita, a escassez e a finitude da água, somadas ao aumento do consumo, à degradação e à poluição, dentre 
outros fatores, fazem da água um bem de atributo econômico (D`ISEP, 2010, p.40). Percebe-se, portanto, um entrelaçamento entre o meio ambiente e a economia, que devem ser compatibilizados para se alcançar um desenvolvimento hidrossustentável.

\subsection{O domínio das águas}

O domínio sobre os recursos hídricos reveste-se de grande responsabilidade para com a preservação, manutenção e gerenciamento dos mesmos, objetivando sua perenidade e garantindo os múltiplos usos.

$\mathrm{Na}$ atualidade brasileira, a água é um bem insuscetível de apropriação privada, vez que a Constituição Federal de 1988 extinguiu as águas particulares, não recepcionando o Código de Águas e o Código Civil vigentes na época. Por sua vez, o tratamento da água no Código Civil de 2002 referese aos direitos de vizinhança (Direito das Coisas, Capítulo V, Dos direitos de Vizinhança, Seção V, Das Águas, artigo 1.288 a 1.296), preocupando-se com a regulação das relações individuais decorrentes da vida em sociedade, atribuindo caráter de direito privado aos problemas relacionados à água. Todavia, destaca-se que o proprietário é legalmente impedido de retirar, reter ou interromper o curso de águas situadas na propriedade ou que a atravessem.

Nesse viés, a compreensão dos recursos hídricos, em sintonia com os ditames constitucionais, parte da sua percepção como bem socioambiental, pois a propriedade possui uma função social e, para tanto, deve contemplar interesses coletivos e garantir a promoção do bem comum. O proprietário do prédio não possui poder sobre a propriedade de águas doces, mas possui o dever de usar e, se for o caso, dar uma destinação em consonância com interesses sociais. Conforme o atual regime jurídico hídrico, as águas são recursos naturais e integram os requisitos essenciais ao cumprimento da função social da propriedade. (GUIMARÃES, 2013, p.115-116).

O legislador adotou os critérios da extensão, ao mencionar que as águas superficiais pertencem à União quando os rios ou lagos banham mais de um Estado, e da segurança nacional, quando servem de limites com outros países, estendem-se a território estrangeiro ou dele provêm, bem como os terrenos marginais e as praias fluviais. As demais águas são do domínio dos estadosmembros. 
Por forca da atual Lei Maior, todas as águas são públicas, de domínio da União ou dos Estados e, por analogia, do Distrito Federal, não mais existindo águas comuns ou particulares. Em síntese, conclui Édis Milaré (2011, p.592) que "não mais subsiste o direito de propriedade relativamente aos recursos hídricos. E os proprietários passam à condição de meros detentores dos direitos de uso dos recursos hídricos, assim mesmo, desde que obtenham a necessária outorga prevista na lei."

Por seu turno, os recursos naturais com potencial energético, independente de sua localização, pertencem à União, tendo em vista sua relevância econômica. (THOMÉ, 2012, p.471). Observe-se que não existem mais águas particulares nem municipais, todavia, a União e os Estados podem conceder a outorga de direitos de uso de recursos hídricos, o que tão-somente implica simples direito de uso, e não alienação das águas.

O direito à água é um dos corolários responsáveis pela efetivação da publicização do seu domínio, e a natureza jurídica da água, como direito fundamental universal, é que deve orientar sua gestão. (D“ISEP, 2010, p.58). De fato, o domínio público das águas é que mais se coaduna com as diretrizes constitucionais e tal harmonia exige uma tutela jurídica adequada, acompanhada da de uma efetiva gestão hídrica.

\section{A CONSTRUÇÃO DO ARCABOUÇO JURÍDICO DOS RECURSOS HÍDRICOS NO BRASIL}

O Direito tenta acompanhar a evolução social e uma normatização das águas não é diferente. O tratamento jurídico das águas, antes limitado a conflitos de vizinhança e geração de energia, hoje apresenta um panorama diverso e passa a exigir uma tutela sistêmica, que vislumbre a água como um bem comum, essencial à sadia qualidade de vida e dotada de usos diversos.

Interessa dizer que todos os instrumentos jurídicos, econômicos, sociais, ambientais que viabilizam o acesso à água são de aplicação legítima e, como ensina Clarissa Macedo Ferreira D“Isep (2010, p.59), “a vida tutelada pelo sistema jurídico não se limita à existência física (o que garante o acesso gratuito à água), e sim a uma vida qualificada, qual seja, a vida digna”, e esta não se perfaz sem a disponibilidade hídrica adequada. Sendo assim, a política ambiental deve ser construída com vistas à concretização da dignidade de gerações presentes e futuras, disponibilizando recursos hídricos em quantidade e qualidade suficientes. 


\subsection{Evolução legislativa}

O grande desenvolvimento experimentado pelo país na segunda metade do século XX exigiu maior aporte energético. Nesse contexto, foi criado o Código de Águas, pelo Decreto n. ${ }^{\circ} 24.643$, de 10 de julho de 1934, considerado o marco legal do gerenciamento dos recursos hídricos no Brasil, cujas normas priorizavam a proteção dos recursos hídricos direcionados para a produção de energia, não se preocupando com sua preservação e conservação.

Com o advento de outras atividades econômicas que exigiam maior consumo de água, criaram-se mecanismos de regulação, dentre os quais se destacam a Lei no 6.938/81, que institui a Política Nacional do Meio Ambiente, alterada posteriormente pela Lei $n^{\circ} 7.804 / 89$, e a Resolução CONAMA n ${ }^{\circ}$ 237/ 97, que disciplina o Licenciamento Ambiental.

Todavia, o acelerado processo de industrialização resultou em grande degradação ambiental, tornando indispensável uma nova disciplina jurídica para tutela ambiental, papel absorvido pela Constituição da República de 1988.

A Carta constitucional representou um divisor de águas na defesa ambiental, não apenas por erigir o meio ambiente como direito fundamental, mas também por dedicar-lhe um capítulo exclusivo, extinguir o domínio privado das águas e condicionar a atividade econômica à preservação ambiental. $\mathrm{Na}$ verdade, a implementação da nova ordem constitucional adveio com a edição da Lei Federal n ${ }^{\circ}$ 9.433, de 08.01.1997, cujos fundamentos serão tratados adiante.

\section{Código de Águas}

Gestado em uma época em que o país deixava de ser um país essencialmente agrícola, após trinta anos de dormência, foi aprovado o Código de Águas, Decreto n. 24.643, de 10.07.1934. Foi a primeira legislação que disciplinou o regime jurídico das águas propriamente dito. Atendendo às exigências da época, possibilitava que o Poder Público disciplinasse o aproveitamento industrial das águas, especialmente a exploração da energia hidráulica.

Ao prever que o uso comum das águas podia ser gratuito ou retribuído, de acordo com as leis e os regulamentos da circunscrição administrativa a que pertencessem, o Código de Águas não apenas assegurava o uso gratuito para as necessidades básicas da vida, como também inovou ao prever o pagamento pelo uso da água e instituir, ainda que de forma incipiente, o princípio do poluidorpagador. 
Todavia, na década de setenta, outras atividades demandavam maior aporte de recursos hídricos e, seus usuários, desafiando a prioridade atribuída à energia elétrica, despertaram para a reforma no sistema de gestão dos recursos hídricos do Brasil. Não obstante ter sido o Código de Águas um importante marco jurídico, os usos múltiplos, a manutenção das reservas hídricas e da qualidade da água, dentre outros temas relevantes, careciam de regulamentação. Nesse contexto, a emergente necessidade de modernização do setor hídrico e a convivência com a Política Nacional do Meio Ambiente reforçaram ainda mais a revitalização do Código de Águas.

\section{A Política Nacional de Meio Ambiente (Lei 6.938/81)}

Em 31 de agosto de 1981, surge a Lei ${ }^{\circ}$ 6.938, que institui a Política Nacional do Meio Ambiente, passando a coexistir com o Código de Águas. Nessa esteira, cumpre salientar que a integração dos dois sistemas normativos é imprescindível para o alcance dos objetivos que, a bem da verdade, são convergentes, uma vez que a água integra o meio ambiente e é afetada por eventuais modificações nele ocorridas.

A instituição da cobrança do uso da água alinha-se às diretrizes da Lei $n^{\circ} 6.938 / 81$, que incluiu a possibilidade de impor ao poluidor e ao degradador a obrigação de recuperar e/ou indenizar os danos causados e, ao usuário, a contribuição pela utilização de recursos ambientais com fins econômicos.

Posteriormente, com o advento da Constituição Federal de 1988, podese dizer que houve uma revolução no tratamento jurídico das águas, alterando o seu domínio e extinguindo as águas particulares ou comuns, previstas no Código Civil e no Código de Águas.

\section{A proteção das águas na Constituição Federal de 1988}

Ao repartir o domínio das águas entre a União e os Estados, modifica-se profundamente o Código de Águas de 1934, cujos conceitos não foram albergados pelo legislador constituinte. Ao definir que todas as águas pertencem à União ou aos Estados, conforme sua localização, a água passa a figurar como bem público, sendo a extinção do domínio privado da água a alteração constitucional mais significativa.

O gerenciamento dos recursos hídricos, de extrema relevância para o desenvolvimento sustentável da nação, justifica a competência privativa da União, conferida pela atual Constituição Federal, para legislar sobre as águas e 
instituir o Sistema Nacional de Gerenciamento de Recursos Hídricos, além de definir os critérios de outorga de direitos de uso, dentre outros.

Vale ainda dizer que, embora considere os usos múltiplos das águas, o texto constitucional revela que ainda se mantém a preocupação com o aproveitamento dos recursos hídricos para a produção de energia. (MILARÉ, 2011, p.629).

Por sua vez, Estados, Distrito Federal e Municípios possuem competência comum para registrar, acompanhar e fiscalizar as concessões de direitos de pesquisa e exploração de recursos hídricos, mediante concessões da União. E, considerando o domínio público das águas, os Estados começaram a implementar os próprios sistemas de gestão de recursos hídricos.

Entretanto, importa dizer que, tendo em vista a ameaça de escassez hídrica, quaisquer investimentos restam inócuos se não houver uma efetiva gestão de recursos hídricos. Nessa esteira, em atendimento à nova ordem constitucional, surge a Lei das Águas (Lei n. 9.433, de 08.01.1997), não só para acompanhar o desenvolvimento econômico e monitorar o aumento do consumo dos recursos hídricos, como também para priorizar o uso vital e garantir os múltiplos usos, por meio de medidas de consumo compatíveis com a proteção e preservação dos recursos hídricos.

\section{A lei que tutela os recursos hídricos: Lei das Águas}

Em um cenário de privatizações, entrou em vigência a Lei n $n^{0} 9.433$ de 1997, denominada Lei das Águas, inspirada no modelo francês, que instituiu a Política Nacional de Recursos Hídricos (PNRH), com o propósito de planejar e gerir o uso das águas de forma sustentável, contando com a participação popular na sua gestão.

A Lei das Águas é o principal instrumento legislativo nacional de políticas hídricas na atualidade e trouxe mudanças significativas, ao agregar princípios inovadores, já praticados em todos os países que avançaram na gestão de recursos hídricos como França, Holanda e Alemanha, quais sejam: a bacia hidrográfica como unidade de planejamento; usos múltiplos, bem finito e vulnerável; valor econômico da água e gestão descentralizada e participativa. (RODRIGUES FILHO, 1999).

Atualmente, o Sistema Nacional de Gerenciamento de Recursos Hídricos (SINGREH) é composto por todos os órgãos competentes para implementação da política nacional: Conselho Nacional de Recursos Hídricos (CNRH), Conselhos Regionais dos Estados, Agência Nacional das Águas (ANA), Comitês 
de bacia hidrográfica e entidades civis de pesquisa no campo hídrico. A PNRH criou também os institutos da outorga de água para uso exclusivo de particulares e a cobrança pelo uso da água.

Ressalte-se que a Lei ${ }^{\circ}$ 9.984/2000 regulou o artigo 32 da Lei 9.433/ 1997, ao dispor sobre a criação da ANA, órgão executor, que tem como principais atribuições o controle, a outorga e a cobrança pelo uso da água nos rios de domínio da União.

A Política Nacional de Recursos Hídricos visa a assegurar às gerações presentes e futuras a necessária disponibilidade de água, em quantidade e qualidade adequadas aos respectivos usos, a utilização hídrica racional e integrada, com vistas ao desenvolvimento sustentável, e a prevenção e defesa contra eventos hidrológicos críticos de origem natural ou decorrentes do uso inadequado dos recursos naturais.

O artigo $1^{\circ}$ da Lei 9.433/97 apresenta os fundamentos da Política Nacional de Recursos Hídricos, que fornecem elementos importantes para o presente estudo, quais sejam: a água é um bem de domínio público, é um recurso natural limitado, dotado de valor econômico; em situações de escassez, o uso prioritário dos recursos hídricos é o consumo humano e a dessedentação de animais; a gestão dos recursos hídricos deve sempre proporcionar o uso múltiplo das águas; a bacia hidrográfica é a unidade territorial para implementação da Política Nacional de Recursos Hídricos e atuação do Sistema Nacional de Gerenciamento de Recursos Hídricos e a gestão dos recursos hídricos deve ser descentralizada, contando com a participação do Poder Público, dos usuários e das comunidades. (BRASIL, 1997a).

Tendo em vista que a água é um bem de domínio público, além de servir ao abastecimento humano, deve beneficiar, indistintamente, outros usuários, de forma a proporcionar os diversos usos como a irrigação na agricultura e atividades industriais (THOMÉ, 2012, p.476). Dessa forma, a outorga não pode sustentar o privilégio de um setor usuário, como ocorre com o setor hidrelétrico no Brasil, que comanda o processo de gestão dos recursos hídricos superficiais, o que gera assimetria de tratamento e inegáveis prejuízos a outros setores dependentes dos recursos hídricos. (MILARÉ, 2011, p.604).

Nessa esteira, aponta-se que os usos múltiplos não podem apenas se direcionar às demandas de uso, devem observar as características da bacia hidrográfica como capacidade, drenagem, características geográficas, topográficas e culturais. Com essa preocupação, o legislador federal inovou ao adotar a bacia hidrográfica como unidade territorial para implementação 
da PNRH e atuação do SINGREH. Contudo, essa forma de administração hídrica, que traduz a democracia mediante a participação da comunidade nos comitês de bacia, caminha a passos lentos e desiguais no território nacional, como também apresenta limitações quando se depara com a dupla dominialidade das águas. Nesse sentido exemplifica Paulo Affonso Leme Machado (2002, p.35):

Por exemplo, se o curso de água principal for federal e os cursos de água tributários forem estaduais, quem administrará a bacia hidrográfica, inclusive efetuando a outorga dos recursos hídricos? A União ou os Estados? O futuro vai dizer se a ideia dessa nova administração hídrica ficou só no terreno da imaginação ou se uma nova descentralização pode ser realizada, com a alteração constitucional da partilha das águas entre União e Estados, para que estas sejam realmente geridas pelos novos organismos hídricos.

Realmente o país ainda está se adaptando à Política de Recursos Hídricos e espera-se que se alcance um sistema de gestão efetivo apto a promover a sustentabilidade hídrica e que conte com a participação da sociedade civil organizada, ainda pouco atuante, visto que a resposta social é de extrema valia na implementação da gestão descentralizada dos recursos hídricos.

Nota-se que um número muito acanhado em face dos inúmeros rios e bacias federais existentes no país e, infelizmente, os Comitês mais ativos ainda não se valem, de forma satisfatória, dos instrumentos de gestão, o que implica dizer que um Comitê sem instrumento operacional é destituído de valor. Ousa-se, portanto, questionar se há interesse por parte do poder estatal em instalar e fazer com que esses modelos gestão realmente funcionem, diante da retirada de uma parcela de poder das suas mãos. Tal realidade leva a crer que os postulados da Lei no 9.433 dificilmente se concretizarão se o Estado se negar a viabilizar a implementação dos instrumentos da Política Nacional de Recursos Hídricos. (ASSIS; LORENTZ, 2012).

Dentre os instrumentos disponíveis na Lei das Águas, que são imprescindíveis para a concretização dos princípios do direito de águas, destaca-se a outorga, a cobrança e os planos de recursos hídricos. A Lei ${ }^{\circ}$ 9.433/1997 coloca a serviço da Política Nacional do Meio Ambiente a outorga de direitos de uso de recursos hídricos, por meio da qual o poder público atribuiu a terceiros uma determinada disponibilidade hídrica, para fins determinados, por certo intervalo de tempo. 
A origem do instituto da outorga do direito de uso das águas remonta ao Código de Águas, que não empregava esta terminologia, referindo-se à "concessão administrativa" e "autorização administrativa", conforme se tratasse, respectivamente, do uso de águas em caso de utilidade pública ou para outras finalidades. (MILARÉ, 2011, p.907).

A outorga é um instrumento que encontra assento constitucional e tem como escopo a promoção do controle quantitativo e qualitativo dos usos das águas e o controle efetivo do exercício dos direitos de acesso à água, preservando os usos diversos. Sendo assim, a outorga está condicionada às prioridades de uso estabelecidas nos Planos de Recursos Hídricos (THOMÉ, 2012, p.482).

No que tange à natureza jurídica da outorga, Sirvinskas (2012, p.384) afirma que ela "[...] é um ato administrativo, na modalidade de autorização administrativa, que permite aos particulares o uso da água em condições e limites estabelecidos na legislação e por tempo determinado [...]”.

Há que se considerar que a adoção de um novo paradigma de gestão dos recursos hídricos, com a valoração econômica, exige não só a outorga como também a utilização da cobrança pelo uso dos recursos hídricos, como instrumento regulatório. A cobrança efetiva o princípio da internalização dos custos ambientais por aqueles que se aproveitam das águas, apropriandose de um bem de uso comum do povo.

Interessa destacar que a cobrança e a outorga para os usos da água são instrumentos que se interagem. O Sistema de Gestão de Recursos Hídricos, por meio da outorga, não apenas controla o uso racional dos recursos hídricos e garante a disponibilidade aos usuários, como também oferece subsídios à cobrança pelo uso dos recursos hídricos.

Cumpre salientar que o sistema de informações sobre recursos hídricos oferece um importante banco de dados sobre eles e fatores atinentes à sua gestão. Tendo em vista as diferentes realidades regionais, conforma um instrumento de extrema valia para reunir e divulgar dados sobre a avaliação quantitativa e qualitativa dos recursos hídricos no Brasil, fornecendo subsídios para que a elaboração dos Planos de Recursos Hídricos regionais, estaduais e nacionais se harmonize com os diferentes contextos hídricos.

Diante dos fundamentos traçados acerca da gestão dos recursos hídricos no território nacional e seus respectivos instrumentos, abre-se a discussão sobre o caminho tortuoso a ser perseguido para a concretização da publicização dos recursos hídricos e o uso sustentável dos mesmos. 


\section{OS DESAFIOS PARA A CONSOLIDAÇÃO DAÁGUA COMO BEM PÚBLICO}

Como já dito alhures, o Código de Águas e Código Civil tinham um olhar essencialmente privatístico em relação à dominialidade das águas, salvo algumas disposições que o primeiro estabelecia em relação ao aproveitamento das águas para navegação, às águas para as primeiras necessidades e às águas públicas. Ainda que a Constituição da República tenha extinguido as águas particulares, as dificuldades para a concretização da dominialidade pública dos recursos hídricos persistem.

\subsection{A inserção das águas no Código Civil}

O atual Código Civil de 2002, espelhando-se nas legislações passadas, refere-se às águas nos artigos 1.288 a 1.296, adstritas a "Direitos de Vizinhança", insertos no título que trata da "Propriedade". Dentre referidos artigos, procedese à análise dos artigos 1.288 e 1.290 que dispõem, sucessivamente:

Art. 1.288. O dono ou o possuidor do prédio inferior é obrigado a receber as águas que correm naturalmente do superior, não podendo realizar obras que embaracem o seu fluxo; porém a condição natural e anterior do prédio inferior não pode ser agravada por obras feitas pelo dono ou possuidor do prédio superior.

$[\ldots]$

Art. 1.290. O proprietário de nascente, ou do solo onde caem águas pluviais, satisfeitas as necessidades de seu consumo, não pode impedir, ou desviar o curso natural das águas remanescentes pelos prédios inferiores. (BRASIL, 2002).

Verifica-se a concepção privatística que o Código Civil devotava às águas, de cunho eminentemente individual, direcionado à exploração econômica, com foco nas águas pluviais ${ }^{1}$ ou nas que brotam das nascentes, tutelando a normalidade de seu curso natural. Havia também, embora em menor medida, uma preocupação com as necessidades de consumo dos proprietários de prédios confinantes.

\footnotetext{
${ }^{1}$ A questão relativa à dominialidade das águas pluviais não ganhou tratamento explícito na Constituição Federal de 1988. (FIGUEIREDO, 2010, p.266).
} 
A desconsideração das águas como um bem em si, ou seja, a "coisificação" das águas e sua inserção no direito de propriedade no Código Civil, certamente pode ser explicada por formulações como a de Dionysio Gama (apud FIGUEIREDO, 2010, p.266), ao ensinar que:

As águas pluviais têm o caráter de res nullius, isto é, de coisas sem dono, por cujo motivo pertencem, por ocupação (e não, por acessão) ao dono ou proprietário do terreno em que elas caem, ou correm, podendo ser por ele apanhadas ou colhidas, guardadas ou reservadas, e aproveitadas, de acordo com as suas necessidades. Quem se assenhorear de coisa abandonada, ou ainda não apropriada, dispõe o art. 592 do Código Civil [atual art. 1.263 do Código Civil de 2002], para logo lhe adquire a propriedade, não sendo essa ocupação defesa por lei. A parte não apanhada, não reservada ou não aproveitada poderá ser utilizada, sem limitações, por qualquer proprietário dos terrenos, por onde for passando, sendo, porém, obrigados os mesmos proprietários a observar os regulamentos administrativos $[\ldots]$.

Em outra passagem em que se realça o caráter essencialmente privado das águas, o autor arremata que:

[...] sendo, unicamente, permitido fazer-se a sua ocupação mediante o uso do prédio, onde correm, certamente não poderiam ser ocupadas por terceiro, sem ofensa do direito de propriedade, que é, de sua essência e natureza, exclusivo, sem outros limites que não sejam os estabelecidos na lei. (GAMA apud FIGUEIREDO, 2010, p.266).

Em que pese a incompatibilidade de tal visão com o caráter de bem difuso atinente aos recursos naturais, tal postura revela-se compreensível, visto que o objetivo do Código Civil é disciplinar as relações no âmbito da vida privada, escapando-lhe a alçada de temas que transcendam os interesses particulares. Vale ainda destacar que, mesmo posterior à Constituição Federal de 1988 e à Lei ${ }^{\circ}$ 9.433/97, o atual Código Civil (2002) nasceu com os olhos voltados para o passado, tendo em vista o lapso temporal entre sua elaboração e vigência, ou seja, refletia outra realidade social.

Observa-se que a atual legislação civil apresenta dispositivos que se assemelham àqueles presentes no Código de Águas de 1934, compartilhando a concepção privatista voltada para a tutela da propriedade e da atividade econômica. 
Contudo, a lógica que orientava o Código de Águas, que ainda persiste no Código Civil de 2002, considerava particulares as águas que caíssem em terrenos de igual natureza e, por não vislumbrarem a água como um bem ambiental, não havia nenhuma preocupação de cunho preservacionista em relação ao meio ambiente.

\subsection{A Constituição Federal de 1988: um divisor de águas}

Trilhando caminho diverso, a Constituição Federal de 1988 albergou a proteção ambiental no artigo 225, rompendo definitivamente com o paradigma privatístico das águas, como se extrai do artigo 26 ao prescrever que "incluemse entre os bens dos Estados: I - as águas superficiais ou subterrâneas, fluentes, emergentes e em depósito, ressalvadas, neste caso, na forma da lei, as decorrentes de obras da União; [...]”. (BRASIL, 1988).

No mesmo sentido, o art. 20 da Constituição Federal também suprimiu qualquer classificação privatística das águas ao estabelecer que "são bens da União: III - os lagos, rios e quaisquer correntes de água em terrenos de seu domínio, ou que banhem mais de um Estado, sirvam de limites com outros países, ou se estendam a território estrangeiro ou dele provenham, bem como os terrenos marginais e as praias fluviais; [...]". (BRASIL, 1988).

Nota-se que a água é um recurso ambiental, ao lado do solo, do ar e dos elementos da biosfera, conforme a dicção do inciso $\mathrm{V}$ do art. $3^{\circ}$ da Lei n ${ }^{\circ}$ 6.938/ 1981. Ao integrar o meio ambiente natural, passa a ostentar o status de bem público de uso comum do povo, de interesse difuso, cuja gestão, nos termos dos arts. 20, III, e 26, I, é atribuída à União ou aos Estados, conforme sua localização.

A bem da verdade, o domínio público da água reflete o princípio da igualdade, na medida em que visa a garantir o acesso equitativo de todos aos recursos hídricos. Cabe ao Estado apenas administrar um bem pertencente à coletividade, ratificando a extinção das águas particulares. Aliás, é oportuno advertir que os sujeitos envolvidos na gestão dos recursos hídricos não podem desvirtuar a titularidade da água considerada bem ambiental comum e que o uso privado das mesmas deve sujeitar-se à outorga pelo órgão competente.

Se os recursos hídricos não podem mais ser vistos como bens privados, é curial que sejam entendidos, de uma forma ampla, como bens socioambientais de natureza pública e difusa, protegidos pelo status de direitos fundamentais, não só por serem inerentes à vida, como também pelo reconhecimento do acesso à água como um direito humano pela ONU, em 2010. (GUIMARÃES, 2013, p.121). 


\subsection{O desafio para a concretização da água como bem comum, com status de direito fundamental}

Para implementar a titularidade da água como um bem das gerações presentes e futuras, são necessários consectários práticos que estabeleçam a viabilidade dessa garantia. De nada valeria esse reconhecimento se os instrumentos de acesso à água restassem inócuos frente a uma realidade dominada pela injustiça e pelo crescente poderio econômico de grupos consolidados, sem desconsiderar a inexistência de políticas públicas concretas. Esse âmbito de análise é essencial, dada a conexão da água com a manutenção da sobrevivência e com a própria vida. (GUIMARÃES, 2013, p.121).

Se a Lei n ${ }^{\circ}$ 9.433/1997, ao implementar os ditames constitucionais acerca do regime jurídico das águas, estabeleceu que estas são bens de domínio público, constituindo um recurso natural limitado, dotado de valor econômico, e cujo uso é condicionado à concessão de outorga pelo poder público, certamente houve a revogação dos dispositivos esparsos do Código de Águas, vigente na época, que cuidavam das águas particulares.

Segundo a Lei das Águas, as águas são valoradas economicamente. Sendo assim, o uso privado é sujeito à outorga onerosa pelo poder público, mediante o pagamento do preço correspondente. Dessa forma, tanto a outorga como a cobrança possibilitam que, por meio do controle exercido pelo poder público, haja um uso racional da água e controle da escassez, o que segundo Figueiredo (2010, p.268), traduz-se como "um importante aspecto do cumprimento da função social da propriedade, pelo uso sustentável desse bem escasso e indispensável para a vida”.

Vale mencionar que vários fatores concorrem para a escassez dos recursos hídricos e deterioração da sua qualidade, mas o mesmo homem degradador que, deliberadamente, não se preocupou com o estoque das reservas hídricas, tem sua sobrevivência ameaçada e sofre com a escassez hídrica que tende a se agravar, caso não forem adotadas medidas que observem as causas do problema.

Conforme princípios da economia, a escassez conduz ao lucro. Nesse viés, percebe-se que a escassez direciona os recursos hídricos para sua valoração econômica, de forma a reforçar sua proteção. Inclusive, a Lei $\mathrm{n}^{0}$ 9.433/1997² reafirma a postura da Organização das Nações Unidas, ao atribuir

2 "Art. 19. A cobrança pelo uso de recursos hídricos objetiva:

I - reconhecer a água como bem econômico e dar ao usuário uma indicação de seu real valor;

REVISTA DO DIREITO PÚBLICO, Londrina, v.8, n.2, p.35-62, mai./ago.2013 
valor econômico à água na Declaração Universal dos Direitos da Água. Nesse sentido, Clarissa Ferreira Macedo D‘Isep (2010, 196-197) observa que:

A patrimonialização propicia a conscientização social de sua importância, revelando um caráter educacional. Além de contribuir para viabilizar sua autossustentação - recuperação, preservação e acessibilidade qualitativa e quantitativa, deve ser gerida por meio de bacias hidrográficas, primando por um regime em que "água financia água".

Importa enfatizar que a cobrança do uso da água constitui-se um instrumento importante para a internalização dos custos, acesso equitativo ao recurso por todos e garantia dos múltiplos usos. (GRANZIERA, 2006, p.63).

Sobre o assunto, posiciona Milaré (2011,p.912) que a valoração econômica

[...] efetiva o princípio da "internalização" dos custos ambientais por aqueles que se aproveitam dos recursos naturais em geral, e, em particular, das águas. Hoje, esses custos são "externalizados", ou seja, são pagos por toda a sociedade, inclusive por quem não se aproveita do recurso natural. Em contrapartida, quando a sociedade não paga esses custos econômicos, paga-os com a degradação da qualidade ou da quantidade do recurso usado.

Observe-se que, se de um lado, a valoração econômica da água objetiva a preservação, proteção e acesso isonômico à água, de outro, a água transformase, em certa medida, em mercadoria. Ao situar o valor econômico como fundamento, o legislador, de certa forma, expõe a água a perigo quando pensou protegê-la pelo viés econômico, pois corre-se o risco de mercantilizar a água, como já ocorreu em vários países, principalmente tendo em vista que a economia utiliza-se da escassez como ponto de partida para o lucro.

Outro ponto a destacar é que mensurar a água segundo valores econômicos, não implica a sua utilização de forma ilimitada, mediante o pagamento de um preço para o uso, pelo contrário, objetiva-se proteger as reservas hídricas através de um custo que considere o preço da conservação, recuperação e melhor distribuição desse bem. (MACHADO, 2002, p.32).

II - incentivar a racionalização do uso da água;

III - obter recursos financeiros para o financiamento dos programas e intervenções contemplados nos planos de recursos hídricos. 
Art. 20. Serão cobrados os usos de recursos hídricos sujeitos a outorga, nos termos do art. 12 desta Lei." (BRASIL, 1997a).

A valoração econômica é utilizada como medida de racionamento do uso, de forma a garantir o uso prioritário, na escassez, qual seja, o consumo humano e a dessedentação de animais, independentemente de ser a água de domínio público ou privado, para aqueles que eventualmente assim a reconheçam. Trata-se de uso insignificante, que independe de outorga e deve ser fornecido gratuitamente, de forma a consolidar o direito fundamental de acesso à água, pois eventual cobrança representaria a remuneração dos direitos fundamentais. Salienta-se que, neste caso, autoriza-se a cobrança da prestação de serviços da água e não o uso insignificante, o que não deve estimular o desperdício. Espera-se, portanto, um consumo responsável, consciente e ético, por parte da coletividade. (D'ISEP, 2010, p.259-260).

Enfatize-se que o princípio do poluidor-pagador, no plano interno, originouse no Código de Águas (BRASIL, 1934) e somente foi implementado com o surgimento da Lei 6.938/81. Revela-se um princípio de grande importância na preservação da qualidade e quantidade dos recursos hídricos, constitui-se como instrumento pelo qual o poluidor deve pagar por poluir as águas, incidindo em duas órbitas, segundo Maria Luiza Machado Granziera (2006, p.59), "no conjunto de ações voltadas à prevenção do dano, a cargo do empreendedor, e na responsabilidade pela ocorrência do dano". Não menos importante é a instituição do princípio do usuário-pagador, ao determinar o pagamento pelo uso privativo de um bem comum, tendo em vista sua finitude.

Se a água adquiriu um valor econômico, a adoção de um novo paradigma demanda sua gestão por meio de instrumentos regulatórios e econômicos como a cobrança pelo uso dos recursos hídricos que, mais do que um instrumento arrecadador, induz a mudanças para conter o desperdício da água, para garantir os usos múltiplos de forma sustentável, para a consecução de uma justiça hídrica, ao internalizar os custos ambientais por aqueles que se utilizam dos recursos hídricos, que hoje são externalizados, ou seja, são pagos pela sociedade e, quando esta não paga os custos econômicos, paga com a perda quantitativa e qualitativa dos recursos hídricos. (MILARÉ, 2011, p.614).

Importa acrescentar que a experiência internacional demonstra a importância da cobrança do uso da água para assegurar a sustentabilidade dos sistemas de recursos hídricos e também para promover a alocação eficiente dos recursos hídricos, sobretudo em regiões nas quais a escassez relativa lhe 
confere um significativo e crescente valor econômico. (AZEVEDO; BALTHAR; FREITAS, 2000, p.26).

Ao discorrer sobre a natureza jurídica de tal cobrança, Milaré (2012, p.912) manifesta que:

O preço do uso dos recursos hídricos não tem a natureza de imposto, pois este é pago genericamente, sem vinculação a um fim determinado. Não é taxa, porque não se relaciona com a prestação de serviço público. É um preço público, pago pelo uso de um bem publico, no interesse particular, como ocorre, por exemplo, com o estacionamento em vias públicas de intenso tráfego.

Por sua vez, Thomé (2012, p.485) afirma que o valor arrecadado na cobrança pelo uso de recursos jurídicos tem natureza jurídica de tarifa, podendo ser aplicado diretamente na bacia hidrográfica em que foi gerado.

Tendo a natureza de taxa ou não, adverte Milaré (2012, p.486) que “os valores arrecadados devem ser aplicados na bacia hidrográfica em que foram gerados" e, não obstante a cobrança pelo uso dos recursos hídricos tenha por objetivo primordial o fomento da racionalização de sua utilização, também financiam programas previstos nos próprios planos de recursos hídricos. (THOMÉ, 2012, p.486).

Mas há que se ressaltar que essa cobrança pelo uso da água nada tem a ver com o valor da prestação dos serviços de coleta, tratamento e distribuição de água. Ao revés, ela significa a atribuição de valor ao bem em si, independentemente de não sofrer nenhum acréscimo pelo trabalho humano.

Todavia, vale ressaltar que existem fortes grupos estrangeiros interessados na exploração de serviços de tratamento de água e esgoto e o Brasil é um mercado promissor para o alcance de lucros vultosos. Interessadas em se apropriar dos recursos hídricos, aumentam gradativamente os custos dos serviços prestados a ponto de parcela da população não conseguir mais ter acesso à água, por não ter condições de pagar por ela. Assim, silenciosamente, desvirtuase o atual sistema de dominialidade e gerenciamento dos recursos hídricos.

Observa-se também que, muitas vezes, a cobrança da outorga de uso de recursos hídricos, em última análise, acaba desvirtuando o seu objetivo de preservar o meio ambiente e transforma o pagamento na obtenção do direito de uso desses recursos perante o poder público em direito de uso ilimitado, o que, na visão de Figueiredo (2010, p.128), “não contribui para o fortalecimento dos 
princípios de uma ética empresarial socioambientalmente e que tampouco auxilia a proteção da diversidade biológica".

Essa espécie de privatização tem sido muito nociva para vários países que permitiram a exploração dessa atividade econômica e teme-se que, através da aparente inocuidade da privatização, o abastecimento das populações carentes seja comprometido, negando-lhes esse bem ambiental comum, em ofensa frontal ao princípio constitucional da inviolabilidade do direito à vida, previsto constitucionalmente no caput do artigo $5^{\circ}$ da Constituição da República de 1988.

Reafirma-se que inexiste direito subjetivo à livre utilização dos recursos hídricos. Para assegurar e proteger o uso coletivo, exige-se o consentimento prévio do Poder Público para o uso privado de um bem comum, difuso, inalienável, que se instrumentaliza mediante a outorga, o que, segundo artigo 18 da Lei ${ }^{\circ}$ 9.433, "não implica a alienação parcial das águas que são inalienáveis, mas o simples direito de uso". (BRASIL, 1997a).

No mesmo sentido, Machado (2002, p.27) adverte que "o Governo Federal e os Governos Estaduais, direta ou indiretamente, não podem tornar-se comerciantes de águas. A Lei n ${ }^{\circ}$ 9.433/97 introduz o direito de cobrar pelo uso das águas, mas não instaura o direito de venda das águas." Realmente o país ainda está se adaptando à Política de Recursos Hídricos e espera-se que se alcance um sistema de gestão efetivo que promova a sustentabilidade hídrica e que conte com a participação da sociedade civil organizada, que ainda se encontra pouco atuante, visto que a resposta social é de extrema valia na implementação da gestão descentralizada dos recursos hídricos e consolida o exercício da democracia.

É imprescindível que haja participação da sociedade para o alcance dos objetivos estabelecidos na Política Nacional de Recursos Hídricos para a concretização do direito fundamental humano de acesso à água, vez que, infelizmente, poucas unidades de planejamento de gestão federais foram definidas e possuem o Comitê de Bacia criado. É um número muito acanhado em face dos inúmeros rios e bacias federais existentes, no período de vigência da $\mathrm{PNRH}$, sem desconsiderar que, por sua vez, os Comitês criados ainda não dispõem, de forma satisfatória, dos instrumentos de gestão, o que implica dizer que um Comitê sem instrumentos equivale a nada. (ASSIS; LORENTZ, 2012).

Tem-se a ousadia de questionar se há interesse por parte do poder estatal em instalar e fazer com que os modelos gestão realmente funcionem, diante da retirada de uma parcela de poder das suas mãos. De fato, os postulados da Lei das Águas dificilmente se concretizarão se o Estado se negar a viabilizar a 
implementação dos instrumentos da Política Nacional de Recursos Hídricos. (ASSIS; LORENTZ, 2012).

O princípio do desenvolvimento sustentável é essencial para a concretização do direito fundamental à água, na medida em que tende a conciliar interesses sociais, ambientais e econômicos. Todavia, ainda que a legislação hídrica sustente a dominialidade pública dos recursos hídricos, o domínio provado ainda se faz presente. A bem da verdade, é preciso tratar a política nacional de recursos hídricos com mais seriedade.

Não é uma tarefa fácil formular e implementar uma política hídrica com todos os fundamentos, objetivos, diretrizes gerais de ação e instrumentos. $\mathrm{O}$ Estado encontra dificuldades para a efetivação de políticas e normatização de fiscalização administrativa. Os instrumentos previstos na lei, como a outorga, cobrança pelos usos da água e os planos de recursos hídricos, vêm sendo implementados com muitos obstáculos. (GUIMARÃES, 2013, p.119).

Observe-se que os conflitos conduzidos ao Judiciário, circunscritos a direitos de vizinhança, dão lugar a novos conflitos, com outras dimensões, e tendem a se multiplicar, porque muitas discussões já se iniciam em torno de perfuração de poços para captação de águas subterrâneas, contaminação das águas, privatização, outorgas e cobranças de uso, etc. Cabe ressaltar que o que desafia a implementação da Lei n ${ }^{\circ}$ 9.433/97 ainda é a sistematização das leis estaduais em consonância com a mesma Política Nacional de Recursos Hídricos, vez que leis promulgadas anteriormente apresentam dispositivos conflitantes. (GUIMARÃES, 2013, p.120).

Uma gestão efetiva dos recursos hídricos deve integrar também a gestão de outros recursos ambientais como o solo, as florestas, dentre outros, e almejar o bem estar socioeconômico sem comprometer a sustentabilidade dos demais ecossistemas. Na visão de Bergson Cardoso Guimarães (2013, p.131) "a complexidade do ciclo hidrológico vai compor-se com o perfeito funcionamento de uma cadeia que integra as bacias hidrográficas, os efeitos do clima, a biodiversidade e as características do solo".

Como bem enfatiza Granziera (2006, p.50), “o desenvolvimento sustentável é um princípio atinente a toda política ambiental, pois possui interface com a outorga do direito de uso da água, o licenciamento ambiental, os usos múltiplos, a noção de bacia hidrografia como unidade de planejamento e gerenciamento.”.

Diante da inegável aproximação entre o desenvolvimento de atividades econômicas e os impactos ambientais, almeja-se uma harmonia entre a atividade 
econômica e a preservação ambiental para coibir os abusos na utilização da propriedade privada em prejuízo da coletividade. Nesse sentido, a própria Constituição Federal (1988) disponibiliza mecanismos como a aplicação do principio da função social da propriedade, o qual incentiva a preservação ambiental e respeita as questões sociais, pois, de um lado, a consagração do princípio da função social da propriedade fomenta o desenvolvimento sustentável, de outro, o legislador viabiliza a proteção ambiental e igualdade social representada pelo postulado da função social da propriedade. (THOMÉ, 2012, p.801-802).

O planejamento hídrico é o instrumento vetor da gestão das águas, sendo responsável pela elaboração de metas e meios para o uso responsável das águas e sua preservação. A elaboração do plano deve conciliar o desenvolvimento econômico e a satisfação das necessidades sociais e utilização racional dos recursos naturais para, assim, refletir o caráter material do desenvolvimento sustentável. A ordem constitucional e a Lei n ${ }^{\circ}$ 9.433/97 não podem ser simbólicas diante da redução das reservas hídricas.

Espera-se que a economia certamente encontre alternativas para administrar os recursos hídricos, uma vez que os planos de recursos hídricos abrem espaço para os usos múltiplos e racionais da água. A integração da gestão dos recursos hídricos com a gestão ambiental aumenta a responsabilidades da política nacional e envolve a participação social, particularmente na área das bacias, vinculando-se às práticas do desenvolvimento sustentável. (MILARÉ, 2011, p.602).

Ainda que não se possa aprofundar o estudo, registre-se que o consumo ético da água é essencial para a implementação de qualquer gestão hídrica sustentável. Pensar os destinos da água é pensar os destinos da humanidade.

\section{CONSIDERAÇÕES FINAIS}

Inicia-se o século e XXI e percebe-se que a relação do ser humano com a água vem se modificando, a ponto de despertar a necessidade da inclusão de valores sociais e ambientais na definição de politicas hídricas, sem a pretensão de estagnar a economia, mas sim, impondo-se condições para o uso sustentável dos recursos hídricos, de modo que as gerações vindouras tenham seus estoques garantidos.

Diante dos fundamentos apresentados no presente estudo, não se pode olvidar que a água é um bem insuscetível de apropriação privada, vez que a 
Constituição Federal de 1988 rompeu com o paradigma privatístico que revestia o domínio da água presente no Código de Águas de 1934 e no Código Civil. Tal percepção é a que mais se coaduna com o reconhecimento da água como bem ambiental de uso comum do povo.

Ao estabelecer, como fundamento da Política Nacional de Recursos Hídricos, que a água é um bem de domínio público, dotada de valor econômico e que deve atender a diversos usos, o legislador teve a intenção de garantir o acesso à água por todos e promover o seu uso racional.

Todavia, a PNRH encontra muitos desafios pela frente, principalmente no sentido de criar uma consciência sobre a redução da disponibilidade hídrica e a internalização dos custos de uso dos recursos hídricos, principalmente nas atividades que demandam maior quantidade de água como a agricultura, a indústria e a mineração.

No entanto, o caminho para a efetivação do referido direito é tormentoso.

Ainda que não haja dúvidas acerca do domínio público das águas, não basta que o Estado disponha de um aparato jurídico avançado, porque, se os instrumentos de outorga e cobrança dos recursos hídricos não forem "bem" utilizados, dificilmente a água será um bem comum, pelo contrário, será um bem privatizado por grupos econômicos que, muitas vezes, são mais eficientes na busca de seus objetivos puramente econômicos.

A imposição ao usuário da obrigação da contribuir pela utilização dos recursos hídricos com fins econômicos, como manifestação do princípio do usuário pagador, ao invés de constituir um mecanismo para frear o uso indiscriminado da água e racionalizar o seu uso, não pode se transmudar em um mecanismo que legitime o desperdício e a poluição de tais recursos, sob a alegação de que o pagamento por eles assegura ao "comprador" o direito de usá-los ao seu alvedrio.

Não se pode admitir que, de um lado, a outorga de direito de uso de recursos hídricos se degenere em mecanismo aglutinador de recursos financeiros para satisfação do tesouro estatal, e, por outro, se transmude em autorização para o direito de poluir e constitua uma via oblíqua de "privatização" de recursos que, por expressa previsão constitucional, são eminentemente públicos e de natureza difusa.

Valorizar a água é valorizar a vida, e a vida não pode ser privatizada. Considerar a natureza pública dos recursos hídricos é valorizar os usos múltiplos e não supervalorizar a apropriação privada, é cuidar dos solos para evitar os processos erosivos, é promover a agricultura e pecuária sustentável, é incentivar 
o reaproveitamento das águas, é preservar as florestas e matas ciliares, é buscar tecnologias que demandem menor aporte hídrico e buscar outras fontes energéticas e é, sobretudo, desenvolver uma consciência voltada para uma ética ambiental.

Infelizmente, se os problemas ambientais continuarem a ser abordados sob o viés essencialmente econômico, o problema da escassez hídrica continuará sem soluções concretas, o quadro se agravará, e a escassez hídrica continuará gerando lucros para poucos e a desigualdade de muitos.

\section{REFERÊNCIAS}

AMPESSAN FILHO, Elói. Só se preserva o que tem valor econômico: água. Revista Brasileira de Direito Ambiental, São Paulo, Ano 6, v.22, abr./jun. 2010.

ASSIS, Alexandre Camanho; LORENTZ, Juliana Ferreira. Os dez anos da Política Nacional de Recursos Hídricos: esperando em vão. GTÁguas, PGR, 4. CCR, ano 6, n. 11, fev. 2012. Disponível em: $<$ http://

revistadasaguas.pgr.mpf.gov.br/aguas/ edicoes-da-revista/edicao11/materias/ dez_anos>. Acesso em: 21 abr. 2013.

AZEVEDO, L. G. T. de; BALTAR, A. M.; FREITAS, P. A experiência internacional. A cobrança pelo uso da água. In: THAME, A. C. M. (Org.). A cobrança pelo uso da água. São Paulo: IQUAL, 2000.

BRASIL. Constituição (1988). Constituição da República Federativa do Brasil. Disponível em:<http://www.planalto.gov.br/ccivil_03/constituicao/ constituicaocompilado.htm>. Acesso em: 22 abr. 2013.

BRASIL. Decreto n. 24.643, de 10 de julho de 1934. Decreta o Código de Águas. Disponível em: $<$ http://www.planalto.gov.br/ccivil_03/decreto/ D24643compilado.htm>. Acesso em: 22 abr. 2013.

BRASIL. Lei n. 10.406, de 10 de janeiro de 2002. Institui o Código Civil. Disponível em:<http://www.planalto.gov.br/ccivil_03/leis/2002/ L10406compilada.htm>. Acesso em: 22 abr. 2013. 
BRASIL. Lei n. 9.984, de 17 de julho de 2000. Dispõe sobre a criação da agência Nacional de Águas - ANA, entidade federal de implementação da Política Nacional de Recursos Hídricos e de coordenação do Sistema Nacional de Gerenciamento de Recursos Hídricos, e dá outras providências. Disponível em: < http://www.planalto.gov.br/ccivil_03/leis/19984.htm>. Acesso em: 22 abr. 2013.

BRASIL. Lei n. 9.433, de 8 de janeiro de 1997. Institui a Política Nacional de Recursos Hídricos, cria o Sistema Nacional de Gerenciamento de Recursos Hídricos, regulamenta o inciso XIX do art. 21 da Constituição Federal e altera o art. 1. ${ }^{\circ}$ da Lei 8.001, de 13 de março de 1990, que modificou a Lei 7.990, de 28 de dezembro de 1989. Disponível em: <http:// www.planalto.gov.br/ccivil_03/LEIS/19433.htm>. Acesso em: 22 abr. 2013.

BRASIL. Lei n. 7.804, de 18 de julho de 1989. Altera a Lei $\mathrm{n}^{\circ}$ 6.938, de 31 de agosto de 1981, que dispõe sobre a Política Nacional do Meio Ambiente, seus fins e mecanismos de formulação e aplicação, a Lei $n^{0} 7.735$, de 22 de fevereiro de 1989, a Lei ${ }^{\circ} 6.803$, de 2 de julho de 1980, e dá outras providências. Disponível em: <http://www.planalto.gov.br/ccivil_03/leis/ 17804.htm>. Acesso em: 22 abr. 2013.

BRASIL. Lei n. 6.938, de 31 de agosto de 1981. Dispõe sobre a Política Nacional do Meio Ambiente, seus fins e mecanismos de formulação e aplicação, e dá outras providências. Disponível em: $<\mathrm{http}: / /$ www.planalto.gov.br/ccivil_03/leis/L6938compilada.htm>. Acesso em: 22 abr. 2013.

BRASIL. Ministério do Meio Ambiente. Resolução CONAMA n. 237, de 19 de dezembro de 1997. Regulamenta os aspectos de licenciamento ambiental estabelecidos na Política Nacional do Meio Ambiente. Disponível em: $<$ http://www.mma.gov.br/port/conama/legiabre.cfm?codlegi=237>. Acesso em: 22 abr. 2013.

D‘ISEP, Clarissa Ferreira Macedo. Água juridicamente sustentável. São Paulo: Revista dos Tribunais, 2010.

FIGUEIREDO, Guilherme José Purvin de. A propriedade no direito ambiental. 4. ed. São Paulo: Revista dos Tribunais, 2010. 
GUIMARÃES, Bergson Cardoso. A implementação da tutela jurídicoambiental dos recursos hídricos no Brasil. In: BADINI, Luciano (Coord.). Meio Ambiente. Belo Horizonte: Del Rey, 2013.

GRANZIERA, Maria Luiza Machado. Direito de águas: disciplina jurídica das águas doces. 3. ed. São Paulo: Atlas, 2006.

MACHADO, Paulo Affonso Leme. Recursos hídricos: Direito brasileiro e internacional. São Paulo: Malheiros, 2002.

MACHADO, Paulo Affonso Leme. Direito ambiental brasileiro. 19.ed. São Paulo: Malheiros, 2011.

MILARÉ, Édis. Direito do ambiente: a gestão ambiental em foco: doutrina, jurisprudência. 7. ed. rev., atual e reform. São Paulo: Revista dos Tribunais, 2011.

MILARÉ, Édis. Direito do ambiente: a gestão ambiental em foco: doutrina, jurisprudência. 8. ed. rev., atual e reform. São Paulo: Revista dos Tribunais, 2012.

RODRIGUES FILHO, L. C. S. S. Bacias hidrográficas: nova gestão de recursos hídricos. Mesa 3: Instrumentos Econômicos e Políticas Públicas para a Gestão Ambiental. In: ENCONTRO NACIONAL - SOCIEDADE DE ECONOMIA ECOLÓGICA, 3., 1999, Recife. Anais... Recife: UFPE, 1999.

SIRVINSKAS, Luís Paulo. Manual de direito ambiental. 10.ed. rev., atual. e ampl. São Paulo: Saraiva, 2012.

THOMÉ, Romeu. Manual de direito ambiental. 2. ed. Salvador: Ed. Jus Podivm, 2012.

Recebido em: 2013-06-18 Aprovado para publicação em: 2013-08-13

Como citar: ARMANDO, Nicanor Henrique; VALADÃO, Maristela Aparecida Oliveira. A dominialidade privada dos recursos hídricos em face do desenvolvimento sustentável. Revista do Direito Público, Londrina, v.8, n.2, p., mai/ago.2013. DOI: 10.5433/1980511X.2013v8n2p 